\title{
Influência do bem-estar psicossocial do idoso no enfrentamento de adversidades em saúde: relato de experiência
}

Influence of the psychosocial welfare of the elderly in the facing of health adversities: experience report Influencia del bienestar psicosocial de las personas mayores ante las adversidades en salud: informe de experiencia

\begin{abstract}
RESUMO
Objetiva-se relatar a experiência de atividades de abordagem familiar realizadas com uma paciente idosa, de amplo histórico de enfrentamento de adversidades em saúde e sociais, assistida na Estratégia Saúde da Família. Trata-se de um estudo descritivo, tipo relato de experiência, vivenciado a partir de visitas domiciliares por estudantes do primeiro ano do curso de medicina, sob orientação de duas professoras, em um núcleo familiar residente no Bairro Castelão (Fortaleza/CE). Por meio da aplicação de ferramentas de abordagem familiar, percebeu-se que os fatores psicossociais tendem a influenciar na qualidade de vida, na forma de percepção da doença e na realização das ações de saúde do idoso, o que contribui para o bem-estar na senilidade. A experiência enriqueceu a formação dos discentes ao estimular a ampliação dos conhecimentos voltados para preceitos da Medicina Centrada na Pessoa, incitando o reconhecimento diferenciado do indivíduo, do seu contexto familiar e da sua inserção social.
\end{abstract}

DESCRITORES: Idoso; Saúde do Idoso; Sistemas de Apoio Psicossocial; Visita Domiciliar.

\section{ABSTRACT}

The objective is to report the experience of family approach activities carried out with an elderly patient, broad history of coping with health and social adversities, assisted in the Family Health Strategy. It is a descriptive study, type of experience report, experienced from home visits by first year medical students, under the guidance of two teachers, in a family nucleus resident in neighborhood Castelão (Fortaleza / CE). Through the application of family approach tools, it was noticed that psychosocial factors tend to influence the quality of life, the perception of the disease and the performance of health actions for the elderly, which contributes on the well-being of senility. The experience got rich the formation of students by stimulating the expansion of knowledge focused on the precepts of Person-Centered Medicine, encouraging differentiated recognition of the individual, his family context and his social insertion.

DESCRIPTORS: Aged; Health of the Elderly; Psychosocial Support Systems; House Calls.

\section{RESUMEN}

El objetivo es reportar la experiencia de las atividades de acercamiento familiar realizadas com um paciente anciano, de amplio historial de afrontamiento de adversidades sociales y de salud, assistido em la Estrategia de Salud de la Familia. Es um estúdio descriptivo, tipo de informe de experiencia, experimentado de visitas domiciliares por estudiantes de medicina de primer año, bajo la guía de dos profesores, en un núcleo familiar residente en barrio Castelão (Fortaleza / CE). Mediante la aplicación de herramientas de enfoque familiar, se notó que los factores psicosociales tienden a influir en la calidad de vida, la percepción de la enfermedad y el desempeño de acciones de salud para los ancianos, lo que se contribuye en el bienestar de la senilidad. La experiencia enriqueció la formación de los estudiantes al estimular la expansión de conocimientos centrados en los preceptos de la Medicina Centrada en la Persona, fomentando el reconocimiento diferenciado del individuo, su contexto familiar y su inserción social.

DESCRIPTORES: Anciano; Salud del Anciano; Sistemas de Apoyo Psicosocial; Visita Domiciliaria.

RECEBIDO EM: 15/09/2020 APROVADO EM: 22/10/2020

\section{Elidivane Martins de Freitas Soares}

Acadêmica de medicina da Universidade de Fortaleza (UNIFOR).

ORCID: 0000-0002-3396-0978 


\section{Gerídice Lorna Andrade de Moraes}

Professora de medicina da Universidade de Fortaleza. Articuladora da Atenção Primária à Saúde- SMS. Conselheira Nacional de Saúde - CNS. Enfermeira. Doutora em saúde coletiva pela Universidade Federal do Ceará (UFC). Mestre em saúde coletiva pela Universidade Federal do Ceará.

ORCID: 0000-0002-7097-0841

\section{Júlia Albuquerque Feitosa}

Acadêmica de medicina da Universidade de Fortaleza (UNIFOR). ORCID: 0000-0002-8427-4628

\section{Paola Maria Barros Diógenes Pessoa}

Acadêmica de medicina da Universidade de Fortaleza (UNIFOR). ORCID: 0000-0002-8228-2931

\section{Viviane de Sousa Oliveira}

Acadêmica de medicina da Universidade de Fortaleza (UNIFOR). ORCID: 0000-0003-1020-2469

\section{INTRODUÇÃO}

$\mathbf{N}$ o panorama brasileiro, é notável o crescimento do percentual de pessoas com mais de 60 anos de idade na composição da sociedade, posto que a quantidade de senis na população aumentou em torno $20 \%$ nos últimos cinco anos e, atualmente, representa quase $14,3 \%$ dos brasileiros ${ }^{1,2}$. Essa transição no perfil demográfico reflete diretamente no viver coletivo, que se acentua com o desenvolvimento de doenças e agravos crônicos não transmissíveis, bem como com o surgimento de estados permanentes ou de longo comprometimento à saúde dos cidadãos. Entre janeiro de $2002 \mathrm{e}$ abril de 2013, foi registrado 199.666 novos cadastros de doenças crônicas, como diabetes e hipertensão, na população acima de 60 anos no estado do Ceará 3 . Além disso, demostrando ainda mais a vulnerabilidade desse grupo social, tem-se também aspectos de fragilidade relacionados a quedas na terceira idade, as quais, de acordo com o Ministério da Saúde ${ }^{4}$, cerca de $30 \%$ das pessoas idosas caem a cada ano, número com tendência ainda maior para as mulheres até os 75 anos, implicando em alta suscetibilidade a lesões. Assim, o envelhecimento humano pode ser apresentado como um processo de declínio progressivo da capacidade adaptativa e compensatória dos seres humanos diante de eventos estressores, associado a mu- danças biológicas, psicológicas e sociais dos indivíduos 5 .

Além disso, o envelhecimento, comumente, traz consigo algumas peculiaridades como mudança nos padrões de saúde, redução na capacidade funcional e a possibilidade de experienciar debilidades que tornem necessário a co-residência com familiares ${ }^{6}$.

Sob esse viés e seguindo as atuais prerrogativas da Organização Mundial da Saúde (OMS), o conceito de saúde é subestimado quando se focaliza exclusivamente no contexto de ausência de doenças, salientando unicamente a dimensão fisiológica dos indivíduos e negligenciando as complexas interações entre dimensões emocional, cognitiva, social e cultural ${ }^{7}$. Portanto, as garantias de saúde do idoso devem prezar pelo bom funcionamento individual na pluralidade, na família e no bem-estar em todas as suas dimensões. Ao se considerar o indivíduo como um todo e com um papel ativo no que diz respeito à sua saúde e doença, há uma imersão na perspectiva biopsicossocial, que, notadamente, vem se sobressaindo como modelo de assistência à saúde e busca integrar fatores biológicos, emocionais e sociais ${ }^{8}$, o que reforça a importância da inserção da pessoa nas relações coletivas como fator fundamental para o melhor enfrentamento de adversidades para a superação de problemas de saúde 9 .
Ademais, destaca-se que os processos psicossociais interferem na formação dos sujeitos, constituindo não só valores, mas sistemas de orientação para a vida, os quais atuam, também, na forma de percepção de enfermidades e na realização e na manipulação das ações de saúde $^{7}$. Nesse contexto, a Estratégia Saúde da Família (ESF) insere-se como facilitadora ideal para atuação centrada em idosos e a experiência com abordagem familiar, durante a formação médica, permite aprender além do conhecimento clínico específico. Posto que o contato com histórias de vida tem um valor importante para o crescimento pessoal e para o amadurecimento do futuro médico, além de proporcionar a compreensão da influência que a família exerce no bem-estar do indivíduo, de modo a preparar o acadêmico de medicina para tratar a pessoa idosa em suas particularidades e em seu contexto de vida ${ }^{10}$.

A partir dessa perspectiva, o presente trabalho foi desenvolvido para apresentar a importância do bem-estar psicossocial para o enfrentamento de problemas de saúde na senilidade, por meio de um relato de experiência da vivência obtida em visitas domiciliares a uma paciente idosa, de amplo histórico de superação de adversidades biopsicossociais, com a finalidade de fortalecer a formação estudantil sobre essa temática pela aplicação prática da abordagem familiar na graduação em medicina. 


\section{MÉTODO}

Trata-se de um trabalho descritivo com abordagem qualitativa, tipo relato de experiência, elaborado no contexto da disciplina Ações Integradas em Saúde I, ministrada no primeiro semestre do curso de graduação em medicina em uma universidade privada da cidade de Fortaleza. As atividades foram desenvolvidas no segundo semestre de 2019, com aplicações de campo nos meses de outubro e novembro do mesmo ano.

Para fins didáticos, o trabalho foi implementado em quatro etapas sequenciais e complementares: estudo teórico sobre mecanismos, estratégias e ferramentas da Atenção Primária a Saúde (APS); apresentação e simulação de casos clínicos; realização de três visitas domiciliares para formação de vínculo com a família e aplicação prática de ferramentas de abordagem familiar; análise de dados, compartilhamento de experiências e reflexões com discentes e tutores, por meio da elaboração de resumo expandido e apresentação do mesmo na forma de seminário de encerramento da referida disciplina, em dezembro de 2019.

A vivência das visitas domiciliares ocorreu junto à família de uma paciente idosa, escolhida aleatoriamente pela equipe de ESF da Unidade de Atenção Primária à Saúde Edmar Fujita, no bairro Castelão, na cidade de Fortaleza/CE, de iniciais MBS, 79 anos. As atividades foram realizadas por três estudantes da referida disciplina, acompanhados por um agente comunitário de saúde e sob supervisão de duas professoras da instituição de ensino.

As três visitas foram norteadas pela aplicação das seguintes ferramentas de abordagem familiar: Genograma familiar, Ecomapa, FIRO e Apgar familiar, que são utilizadas na rotina prática das equipes de ESF. Tais aplicações permitiram a obtenção de dados da paciente índice e de sua família, o que possibilitou o conhecimento do histórico familiar, bem como a aproximação e a construção de vínculo com a paciente índice e sua família, culminando em produtos para discussões e análises so- bre a influência do bem-estar psicossocial na senilidade.

Por se tratar de um relato de experiência, não houve a utilização do Termo de Consentimento Livre e Esclarecido (TCLE). Acrescenta-se que não será divulgado nenhum dado que possibilite identificação dos envolvidos, de acordo com o preconizado pela Resolução n. ${ }^{\circ}$ 466/2012 do Conselho Nacional de Saúde $-\mathrm{CNS}^{11}$.

\section{A vivência das}

visitas domiciliares

ocorreu junto

à família de

uma paciente

idosa, escolhida

aleatoriamente pela

equipe de ESF da

Unidade de Atenção

Primária à Saúde

Edmar Fujita, no

bairro Castelão,

na cidade de

Fortaleza/CE, de

iniciais MBS,

79 anos.

\section{RESULTADOS}

O estudo teórico prévio no ambiente universitário sobre mecanismos da APS e, principalmente, sobre atuação da ESF capacitou os estudantes do primeiro semestre do curso de medicina para realização das visitas domiciliares e condução supervisionada das práticas de abordagem familiar.

No primeiro contato domiciliar, buscou-se obter informações sobre a história familiar, abrangendo aspectos como ciclo de vida, vínculo afetivo, rede de apoio e presença de doenças hereditárias nos integrantes da família, o que subsidiou a elaboração de um genograma familiar, que está apresentado na Figura 01. Esse instrumento possibilitou identificar a estrutura familiar e as conexões estabelecidas entre os membros da família e a paciente índice. Também foi desenvolvido um Ecomapa, representado na Figura 02, por meio da disposição das relações entre a pessoa índice e a comunidade, ilustrando as redes de apoio acessíveis e as vinculações estabelecidas. Já na segunda visita, foi possível ampliar o conhecimento acerca da dinâmica familiar, com a aplicação do modelo "Fundamental Interpersonal Relations Orientation" (FIRO), que facilitou a avaliação de sentimentos dos membros da família nas vivências de relações habituais. Por fim, na terceira visita, foi aplicada a ferramenta Apgar de família ${ }^{12,13}$, que proporcionou o melhor entendimento da funcionalidade e da conectividade familiar, tento obtido o resultado no escore ${ }^{9} \mathrm{e}$ categorizando o enquadramento da estrutura familiar de MBS como família funcional.

\section{DISCUSSÃO}

A análise dos dados iniciou-se com a formação de uma linha do tempo da história familiar e com a leitura esquemática do genograma da família de MBS (Figura 1), identificando-se a representação de 4 gerações familiares e a inserção da paciente na segunda linhagem. Destaca-se que essa senhora teve cortes precoces de relacionamentos com seus pais, que 


\section{artigo}

Soares, E.M.F.; Moraes, G.L.A.; Feitosa, J.A.; Pessoa, P.M..D.; Oliveira, V.S.;

Influência do bem-estar psicossocial do idoso no enfrentamento de adversidades em saúde: relato de experiência

Figura 1 - Genograma do paciente índice - produção dos próprios autores utilizando o programa Power Point.

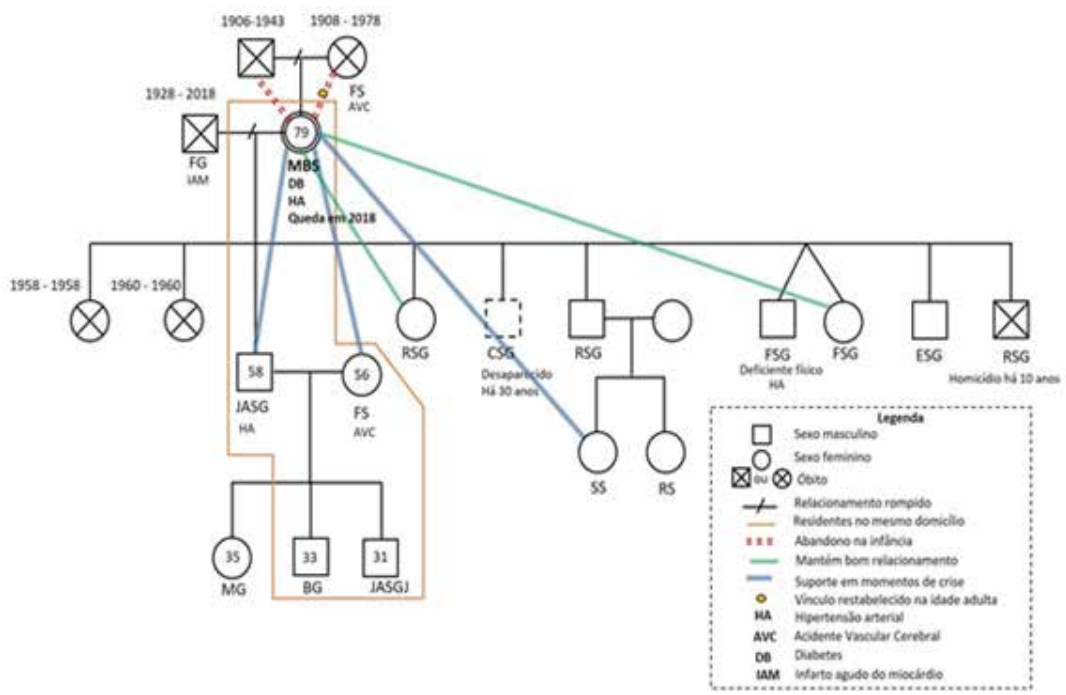

Figura 2 - Ecomapa do paciente índice - produção dos próprios autores utilizando o programa Power Point.

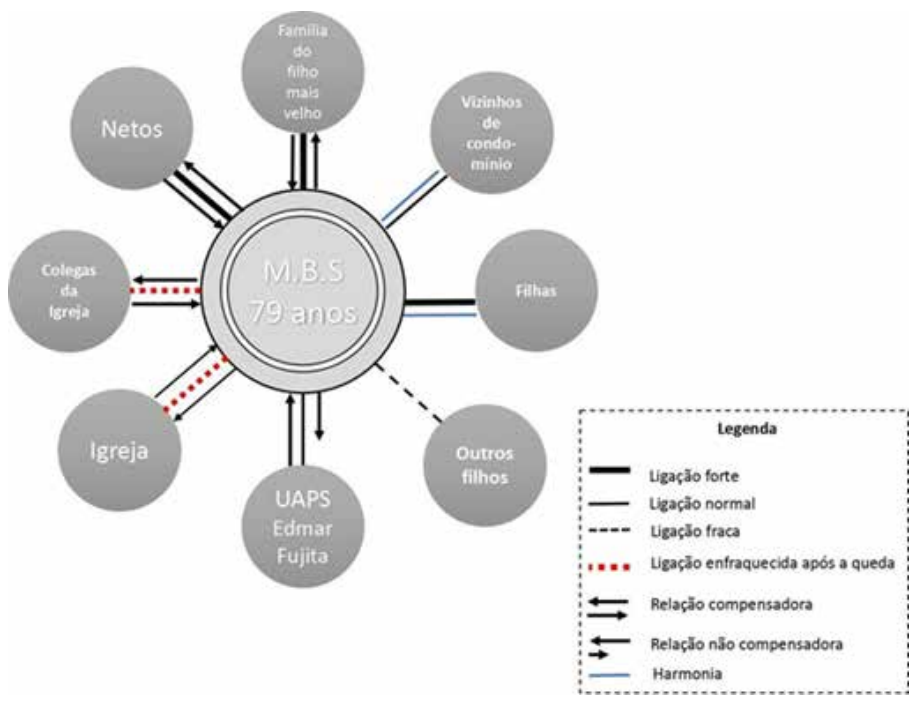

a abandonaram ainda criança e, assim, ela foi adotada por outra família. Anos depois, houve o restabelecimento da relação com sua genitora, após a mesma ser acometida por um acidente vascular cerebral (AVC) e somente MBS se manifestou para cuidar dela. Tal fato ressalta que, mesmo com possíveis fatores traumáticos na infância, que indicavam para
MBS guardar rancor de sua mãe biológica, ela escolheu a compaixão e atuou no cuidar até o óbito da sua genitora, em 1978. Nota-se, também, como fator conflituoso psicoafetivo, a separação com seu ex-marido, FG, quando seus filhos eram crianças, devido a uma possível relação extraconjugal e à fragilidade do vínculo familiar, exigindo da paciente grande es- forço e superação individual para manutenção familiar monoparental.

Em relação aos seus descendentes, MBS teve 10 filhos, dos quais duas meninas faleceram ainda na primeira infância. Atualmente, seis filhos mantêm contato com a paciente, pois um sofreu homicídio e outro está desaparecido. No entanto, somente três têm relação forte com a paciente alvo, que são duas filhas, e JASG, o filho mais velho, que sempre foram o suporte em momentos de crise. Dentre esses momentos, destaca-se uma queda sofrida em 2018, que culminou na co-residência com a família de JASG devido à necessidade de cuidado apoiado.

O exame do Ecomapa (Figura 2) evidenciou a forte religiosidade da paciente e o prejuízo da sua atuação social e eucarística após a queda em 2018. No entanto, notou-se que essa fragilidade na relação com os membros da igreja não afetou a devoção religiosa da paciente, a qual possui grande demonstração de fé e aderência às preconizações do catolicismo. Esse tipo de postura religiosa é importante para o fortalecimento pessoal diante de problemas de saúde, o que favorece, possivelmente, o contentamento psicossocial de MBS e, consequentemente, sua resiliência e qualidade de vida?

Com a aplicação da ferramenta FIRO, observou-se que os familiares residentes de MBS costumam estar sempre presentes na vida dela, principalmente JASG, que assume o controle do cuidar familiar. Por outro lado, em relação ao modo de compartilhar, a paciente índice demonstrou sentir-se um pouco incomodada por ter se tornado dependente dos cuidados da família do seu filho e não ter a privacidade que existia em sua casa anteriormente, já que ela dorme em uma cama improvisada na sala de estar. Entretanto, durante as visitas domiciliares, a paciente se mostrou feliz e satisfeita com a atenção recebida pelas pessoas com quem residia, apresentando bom estado geral de lucidez, de cuidado pessoal e de saúde mental, além de moderada capacidade funcional.

Quanto ao escore 09 obtido na aplicação da ferramenta Apgar da família, categorizando o enquadramento da estrutura familiar 
de MBS como família funcional, mostra-se como uma classificação compatível com as exposições e as percepções obtidas nas visitas, reforçando a importância da boa estrutura familiar para o bem-estar do idoso e, consequentemente, para o melhor enfrentamento de adversidades em saúde ${ }^{14}$.

Desse modo, apesar do grande histórico de enfrentamento de múltiplas adversidades, as poucas queixas reportadas por essa senhora foram relacionadas a saudade da sua casa, da sua redução de autonomia em atividades domésticas e da perda da rotina de atuação eucarística, sem qualquer menção a ressentimento, derrotismo, tristeza ou rancor frente aos diversos agravos vivenciados.

Ademais, diante das avaliações desenvolvidas por meio das ferramentas de abordagem familiar aplicadas neste relato de caso, percebeu-se a resiliência intrínseca com que a paciente enfrenta seus agravos, pois ela procura sempre enxergar o lado positivo das ocorrências adversas. Essa visão de MBS é extremamente importante, porque interfere diretamente no seu autocuidado, criando uma ótica de empoderamento sobre o tratamento e a elevação da autoestima para uma maior adesão terapêutica.

As autoras destacam a relevância do conhecimento adquirido no desenvolvimento das atividades teóricas e práticas sobre preceitos da ESF e da Medicina Centrada na Pessoa, já no início da formação acadêmica, como forma de fortalecimento do cuidado humanizado e do acompanhamento diferenciado do indivíduo em seu contexto familiar e social.

\section{CONCLUSÃO}

Com este relato de experiência foi possível compreender que os fatores psicossociais influenciam nos mecanismos de orientação para vida, na forma de percepção da doença e na realização das ações de saúde para o idoso, o que tende a contribuir positivamente para o bem-estar individual e para o enfrentamento de enfermidades na senilidade.

No mais, o desenvolvimento desse estudo enriqueceu a formação dos estudantes de graduação em medicina ao contribuir para a compreensão prática de princípios da Medicina Centrada na Pessoa, estimulando o reconhecimento diferenciado do indivíduo, de seu contexto familiar e de sua inserção social, fundamentais para o cuidado em saúde.

\section{REFERÊNCIAS}

1. Ministério da Saúde (Brasil) [homepage na internet]. Saúde da pessoa idosa: prevenção e promoção à saúde integral [acesso em 20 mai 2020]. Disponível em: https://saude.gov.br/saudede-a-z/saude-da-pessoa-idosa.

2. Instituto Brasileiro de Geografia e Estatística (Brasil) [homepage na internet]. Número de idosos cresce $18 \%$ em 5 anos e ultrapassa 30 milhões em 2017. [Acesso em 16 out 2020]. Disponivel em: https://agenciadenoticias.ibge.gov.br/agencia-noticias/2012-agencia-de-noticias/noticias/20980-numero-de-idosos-cresce-18-em-5-anos-e-ultrapassa-30-milhoes-em-2017.

3. Ministério da Saúde (Brasil) [homepage na internet]. Departamento de Informática do Sistema Único de Saúde do Brasil - DATASUS. Sistema de cadastramento e acompanhamento de hipertensos e diabéticos - Ceará. Banco de dados. [Acesso em 19 out 2020]. Disponivel em: http://tabnet.datasus.gov.br/cgi/ tabcgi.exe?hiperdia/cnv/hdCE.def.

4. Ministério da Saúde (Brasil). Envelhecimento e saúde da pessoa idosa. Cadernos de Atenção Básica - n. 19. Brasília, DF: 0 Ministério; 2006.

5. Rouquayrol MZ, Gurgel M. Epidemiologia \& saúde. 7a edição. Rio de Janeiro: Medbook; 2013.

6. Torres GV, Reis LA, Reis LA, Fernandes MH, Alves GS, Sampaio LS, et al. Funcionalidade familiar de idosos dependentes residentes em domicílios. Aval. psicol. [Internet]. 2009 Dez [citado 2020 Out 20] ; 8( 3 ): 415-423. Disponível em: http://pepsic.bvsalud.org/scielo.php?script=sci_arttext\&pid=S1677-04712009000300013\&lng=pt.

7. Amorim MISPL. Para lá dos números... aspectos psicossociais e qualidade de vida do indivíduo com Diabetes Mellitus tipo
2 [dissertação]. Porto: Programa de Doutoramento em Saúde Mental - Instituto de Ciências Biomédicas Abel Salazar; 2009.

8. De Marco MA. Do modelo biomédico ao modelo biopsicossocial: um projeto de educação permanente. Revista brasileira de educação médica [Internet]. 2006 [Citado em 19 de outubro de 2020];30(1):60-72. Disponivel em: http://www.scielo.br/scielo. php?script=sci_arttext\&pid=S0100-55022006000100010\&I$\mathrm{ng}=\mathrm{en} \& \mathrm{nrm}=$ iso

9. Abdala GA, Kimura M, Duarte YAO, Lebrão ML, Santos B. Religiosidade e qualidade de vida relacionada à saúde do idoso. Revista de Saúde Pública. Agosto de 2015; 49(55).

10. Gonçalves RJ, Soares RA, Troll T, Cyrino EG. Ser médico no PSF: formação acadêmica, perspectivas e trabalho cotidiano. Revista Brasileira de Educação Médica. 2009;33(3):382-392.

11. Conselho Nacional de Saúde (BR). Resolução n. ${ }^{\circ}$ 466, de 12 de dezembro de 2012. Aprova normas regulamentadoras de pesquisas envolvendo seres humanos. Brasília: Diário Oficial da União, 2013.

12. Smilkstein G. The family APGAR: a proposal for a family function test and its use by physicians. The Journal of Family Practice. 1978 May; 6(6): 1231-1239

13. Duarte YAO. Família: rede de suporte ou fator estressor. A ótica de idosos e cuidadores familiares [tese]. São Paulo. Escola de Enfermagem da USP; 2001.

14. Elias HC, Marzola TS, Molina NPFM, Assunção LM, Rodrigues LR, Tavares DMS. Relação entre funcionalidade familiar e arranjo domiciliar de idosos. Rev. bras. geriatr. gerontol. [Internet]. 2018 [citado em 20 de maio 2020]; 21( 5 ): 562-569. Disponivel em. https://doi.org/10.1590/1981-22562018021.180081. 